\title{
Keap1/Nrf2 pathway in sodium fluoride-induced cardiac toxicity and the prophylactic role of vitamin C versus platelet-rich plasma
}

\author{
H. Labib1', A.M. Badr², M. Abdelgwad², T.I. Abd El-Galil ${ }^{1}$ \\ ${ }^{1}$ Department of Anatomy and Embryology, Cairo University, Cairo, Egypt \\ ${ }^{2}$ Department of Medical Biochemistry and Molecular Biology, Faculty of Medicine, \\ Kasr Alainy, Cairo University, Cairo, Egypt
}

[Received: 19 February 2021; Accepted: 6 May 2021; Early publication date: 17 May 2021]

\begin{abstract}
Background: The present study was conducted to investigate the role of vitamin C versus platelet-rich plasma (PRP) against sodium fluoride (NaF)-induced cardiotoxicity and cell death in rats' myocardium. Previous studies suggest that $\mathrm{NaF}$ decreased cellular viability and intracellular antioxidant power.

Materials and methods and Results: The present study revealed that NaF administration caused histological alterations in the cardiac muscle and increased the accumulation of intracellular reactive oxygen species, the expression of inducible nitric oxide synthases and proliferating cell nuclear antigen as well as collagen deposition in cardiac tissue. As supported by colorimetric analysis, an elevation in malondialdehyde level and a decrease in both superoxide dismutase (SOD) and thioredoxin-1 oxidoreductase (TrX) levels were seen, whereas molecular analysis revealed a decrease in Keap1 and an increase in Nrf2 and HO-1 gene expression. Pretreatment with vitamin $\mathrm{C}$ and PRP prior to $\mathrm{NaF}$ administration significantly improved the altered parameters and enhanced the cellular antioxidant capability of myocardium resulting in protection of cardiac muscle from NaF-induced cytotoxicity and apoptotic cell death.

Conclusions: The cyto-protective activity of PRP was found to be comparable to that of the known antioxidant, vitamin C. (Folia Morphol 2022; 81, 3: 663-678)
\end{abstract}

Key words: sodium fluoride, vitamin C, platelet-rich plasma, Keap1, Nrf2, TrX-1

\section{INTRODUCTION}

Fluoride is an inorganic, mono-atomic anion designated the chemical formula $\mathrm{F}-$, the salts of which are colourless/white, bitter tasting and are neutral in terms of smell. It is used in the manufacture of fluorocarbons. Although classified as a weak base, concentrated fluoride causes skin erosion [27]. Fluoride is mandatory for bones and teeth develop- ment and for minimizing bone fractures. A fluoride concentration of $0.5-1.5 \mathrm{mg} / \mathrm{L}$ in drinking water is favourable, whereas exceeding intake of fluoride is toxic [45]. Fluoride is used in tooth decay prevention and oral hygiene products in the form of sodium fluoride (NaF) or sodium monofluorophosphate. Water fluoridation depends on the fluoride [29]. The United States Department of Agriculture has specified the

Address for correspondence: Ass. Prof. T.I. Abd El-Galil, Department of Anatomy and Embryology, Cairo University, Cairo, Egypt 71 El Kasr Al Ainy street, Greater Cairo, Financial number, 1631, tel: 02-2794782, e-mail: tarek.ibrahim@kasralainy.edu.eg

This article is available in open access under Creative Common Attribution-Non-Commercial-No Derivatives 4.0 International (CC BY-NC-ND 4.0) license, allowing to download articles and share them with others as long as they credit the authors and the publisher, but without permission to change them in any way or use them commercially. 
Dietary Reference Intakes of fluoride to be $10 \mathrm{mg} /$ /day, which is equal to $10 \mathrm{~L}$ of fluoridated water and 0.7 to $2.2 \mathrm{mg} /$ day for the younger population [11]. A dose of 5-10 g (equivalent to $32-64 \mathrm{mg} / \mathrm{kg}$ ) of $\mathrm{NaF}$ is considered to be lethal $[4,16]$.

Substantial histopathological and biochemical changes are seen in the myocardial tissue of rats exposed to chronic NaF ingestion. Myocardial cell necrosis, excessive cytoplasmic vacuolation, karyolysis in myositis and degenerative changes of the myocardial fibres are some of the encountered histopathological changes. In addition, an increase in oxidative stress markers is encountered biochemically. Such histopathological and biochemical changes lead to myocardial tissue damage [9].

Platelet-rich plasma (PRP) is a product of autologous fractionation of whole blood by means of centrifugation that aims to remove blood cells and acquire a concentrate of PRP protein [31]. The platelets in PRP are activated by the addition of thrombin and calcium chloride, enhancing the release of growth factors from their alpha granules [6]. PRP has the ability to modify the oxidative damage seen in skeletal muscle injury by enhancement of myocytes' mitochondrial function and increasing their antioxidant defence mechanisms [28]. PRP promotes angiogenesis in ischaemic heart disease through cell signalling. Although the role of PRP to restore a functional myocardium, either by resettling exogenous or by activating native stem cells, to induce endogenous repair has been recorded in ischaemic heart disease [44], its role in prevention of NaF-induced myocardial damage has not entered broad clinical practice yet.

Vitamin C (ascorbic acid) is a down regulator of oxidative stress and inflammation of the cardiac muscle [12]. Vitamin $C$ causes enhancement of antioxidant capacity, induction of CRYAB and Hsp70 expression, reversal of elevated cardiac enzymes and modification of the histopathological findings in myocardium [50].

Nuclear factor erythroid 2-related factor 2 (Nrf2), also known as nuclear factor erythroid-derived 2-like 2, is a transcription factor encoded by the NFE2L2 gene in humans [30]. Nrf2 is a basic leucine zipper (bZIP) protein that balances the expression of antioxidant proteins, which in turn combat the oxidative stress caused by injury and inflammation [15]. The vasculature has multiple protective means against oxidation and inflammation, many of them being regulated by the $\mathrm{Nrf2}$ transcription factor. Haem oxygenase-1 (HO-1) is a Nrf2-regulated gene that protects against vascular inflammation; it is the inducible isoform of HO. Production of biliverdin, carbon monoxide, and release of ferrous iron occur as a result of an oxidative cleavage of the haem groups achieved by HO-1. It has an antioxidant, anti-inflammatory, anti-apoptotic, anti-proliferative, and immunomodulatory functions in vascular cells [3].

Nrf2 and thioredoxin-1 oxidoreductase (TrX-1) play a significant role in cardiovascular diseases prevention [22]. In cardiomyocytes, TrX-1 induces electron transport chain and the citric acid cycle via PGC-1 alpha and Nrf2 [1], whereas Nrf2 promotes expression of TrX-1 [22]. The Nrf2-induced HO-1 is another feed-forward loop to the TrX-1/Nrf2/TrX-1 axis that alleviates cardiomyocyte apoptosis [39]. Kelch-like $\mathrm{ECH}$-associated protein 1 (Keap1) is the main intracellular regulator of Nrf2. Under basal conditions, Nrf2 is sequestered by cytoplasmic Keap1 and targeted to proteasomal de-gradation [47]. During oxidative stress, the Nrf2-Keap1 interaction is dose-dependent [21]. Free and newly synthesized Nrf2 translocated to the nucleus, influence the expression of many genes coding proteins that serve as antioxidizing agents, detoxifying enzymes, stress response proteins and metabolic enzymes [13].

Malondialdehyde (MDA) is a highly reactive compound that occurs as an enol. It is naturally occurring and is a marker for oxidative stress [33].

Nitric oxide synthases (NOS) are a group of enzymes responsible for catalysing the production of nitric oxide (NO) from L-arginine [10]. Through utilisation of NADPH and O2, NO is produced by three different enzymes belonging to the family of NOS: nNOS/NOS1 (neuronal), iNOS/NOS2 (inducible), and eNOS/NOS3 (endothelial). The activities of nNOS and eNOS demand $\mathrm{Ca} 2+$ for activation and produce NO at nanomolar levels for a short time. On the contra$r y$, iNOS are induced by multiple stressors, without a need for $\mathrm{Ca} 2+$ for activation, and can generate NO at micromolar levels for much longer periods. iNOS, play a role in immune response by binding calmodulin and producing $\mathrm{NO}$ as an immune defence mechanism, since $\mathrm{NO}$ is a free radical with an unpaired electron [20]. We herein evaluate the oxidative stress seen in cardiac muscles of $\mathrm{NaF}$-induced male rats and the role of vitamin $\mathrm{C}$ and $\mathrm{PRP}$ in its prevention.

Proliferating cell nuclear antigen (PCNA), also called 'cyclin', is a 36 KDa nuclear protein which functions as a secondary protein for DNA polymerase delta. PCNA is involved in DNA synthesis and cellular proliferation. PCNA expression lowers during mito- 
sis and is difficult to detect immunohistochemically, but it peaks at the G1/S of interphase for which it is considered to be a histological marker. PCNA expression is also a marker for mitotic activity [46]. The involvement of PCNA in DNA synthesis and cellular proliferation is attributed to its nature as a cell cycle regulatory protein marker. Chromosome recombination, DNA methylation, nucleic acid metabolism and RNA transcription are other cellular processes with which PCNA is associated [52]. The present study investigates the PCNA expression in cardiac muscles of NaF-induced male rats.

In this study, we evaluate the impact of $\mathrm{NaF}$ oral consumption on oxidative stress markers, Keap1, Nrf2 and HO-1 gene expression and histological modifications in rats' myocardium. The prophylactic roles of oral vitamin C and parenteral PRP administration are compared when given as pretreatment prior to $\mathrm{NaF}$ administration.

\section{MATERIALS AND METHODS}

\section{Animals}

Thirty-six adult (2-months-old) male albino Wistar rats weighing approximately $250 \mathrm{~g}$ were purchased from and housed at the animal house at the Faculty of Medicine, Cairo University. The animals were accommodated 6 in a cage, at a constant room temperature of $22 \pm 1{ }^{\circ} \mathrm{C}$ under a $12 \mathrm{~h}$ light: $12 \mathrm{~h}$ dark cycle. Food and water were supplied ad libitum. All procedures were in accordance with the principles of the Ethics Committee, Faculty of Medicine, Cairo University.

\section{Ethical approval}

All protocols for animal experiments were approved by the institutional animal Ethical Committee, Cairo University, Egypt.

\section{Experimental design}

The rats were equally divided $(n=6)$ into six groups where control group (I) received water ad libitum, vitamin C sham control group (II) received $100 \mathrm{mg} / \mathrm{kg}$ body weight (bw)/day of vitamin C, PRP sham control group (III) received $0.5 \mathrm{~mL}$ of PRP, $\mathrm{Na}$ fluoride group (IV) received NaF at a dose of $25 \mathrm{mg} /$ $/ \mathrm{kg}$ bw/day (which was $1 / 10$ of the oral LD50 values in rats) as recommended by Chinoy [8], Na fluoride + + vitamin C group (V) pre administered with vitamin C daily ( $100 \mathrm{mg} / \mathrm{kg} \mathrm{bw} /$ day) $90 \mathrm{~min}$ before the administration of $\mathrm{Na}$ fluoride at a dose similar to group IV and
$\mathrm{Na}$ fluoride + PRP group (VI) pre administered with $0.5 \mathrm{~mL}$ of PRP daily $90 \mathrm{~min}$ before the administration of $\mathrm{Na}$ fluoride at a dose similar to group IV and $\mathrm{V}$. $\mathrm{Na}$ fluoride and vitamin $\mathrm{C}$ were administered orally via gastric intubation using an intravenous cannula, whereas PRP was injected intraperitoneally. For all groups, the duration of the experiment was 4 weeks.

On the $30^{\text {th }}$ day, blood samples were collected from all rats by means of retro-orbital sampling under general anaesthesia by use of sodium pentobarbital (40 $\mathrm{mg} / \mathrm{kg}$, i.p.). Then the rats were sacrificed by decapitation. The hearts were removed and tissue samples were taken from the heart of each rat for biochemical and histological assessment. For biochemical analyses, the tissue samples were labelled in glass bottles and frozen at $-80^{\circ} \mathrm{C}$ to be studied later.

\section{Chemicals}

Vitamin $C$ tablets were purchased from Sigma Chemical Co. (St. Louis, MO). Each tablet $(100 \mathrm{mg})$ of vitamin $C$ was crushed and dissolved in $2 \mathrm{~mL}$ of distilled water to acquire a $50 \mathrm{mg} / \mathrm{mL}$ suspension and was prepared just prior to administration of $\mathrm{Na}$ fluoride was purchased from Sigma Chemical Co. (St. Louis, $\mathrm{MO}$ ) in powder form and dissolved in normal saline.

Preparation of PRP was done by enrichment of whole blood platelets using a 2-step centrifugation technique. A $10 \mathrm{~mL}$ volume of whole blood was obtained from 6 randomly-picked rats into pre-chilled tubes containing anticoagulant citrate dextrose solution $A(A C D-A)$ at a blood/ACD-A ratio of 9:1. Centrifugation of the blood samples followed, at $400 \mathrm{~g}$ for $10 \mathrm{~min}$ to obtain the three typical layers: red blood cells at the bottom, a 'buffy coat' layer in the middle and acellular plasma in the supernatant. Using a sterile pipette, the upper layer and buffy coat were transferred to another neutral tube and re-centrifuged at $800 \mathrm{~g}$ for $10 \mathrm{~min}$. Approximately, $1 \mathrm{~mL}$ of PRP was collected from the bottom of the tube (for a total of $6 \mathrm{~mL}$ of PRP solution from 6 rats). The total platelet count in each sample of PRP was determined under a phase contrast microscope. Concentrations of the platelets in the two groups receiving PRPs were $692.458 \pm 60.287 / \mu \mathrm{L}$ and $0.5 \mathrm{~mL}$ of PRP was then administered intraperitoneally.

\section{Biochemical analysis}

Homogenation of tissue samples was achieved by washing the heart samples with distilled water to wash out the remaining blood. A 10\% homogenate $(1000 \mathrm{U})$ from each sample was obtained at 5-min 
Table 1. Details about the base sequences of the primers used

\begin{tabular}{|c|c|c|}
\hline Gene & Name & Direction and primer sequence $\left(5^{\prime}-3^{\prime}\right)$ \\
\hline Keap1 & Kelch-like ECH-associated protein 1 & $\begin{array}{l}\text { Forward: 5'-TTCGCCTACACGGCCTC-3' } \\
\text { Reverse: 5'-GAAGTTGGCGATGCCGATG-3' }\end{array}$ \\
\hline Nrf2 & Nuclear factor E2-related factor 2 & $\begin{array}{l}\text { Forward: 5'-TCTGACTCCGGCATTCACT-3' } \\
\text { Reverse: 5'-GGCACTGTCTAGCTCTTCA-3' }\end{array}$ \\
\hline HO-1 & Haem oxygenase 1 & $\begin{array}{l}\text { Forward: 5'-CGTGCAGAGAATCTGAGTTC-3' } \\
\text { Reverse: 5'- AGACGCTTTACGTAGTGCTG-3' }\end{array}$ \\
\hline GAPDH (internal control) & Glyceraldehyde 3-phosphate dehydrogenase & $\begin{array}{l}\text { Forward: 5'-CACCCTGTGCTTGTAGCCATATTC-3' } \\
\text { Reverse: 5'GACATCAAGAAGGTGGTGAAGCAG-3' }\end{array}$ \\
\hline
\end{tabular}

intervals in a homogenator (IKA Labor Technic UItra-Turrax T 25 model) with $150 \mathrm{mM}$ cold $\mathrm{KCl}$. The homogenates were then centrifuged at $6000 \mathrm{xgat}+4^{\circ} \mathrm{C}$ for $10 \mathrm{~min}$ for supernatants to be obtained. Protein concentrations of supernatant were determined by real time quantitative polymerase chain reaction (PCR).

\section{Real time quantitative PCR of studied genes}

Total RNA was extracted from heart tissue homogenate with RNA easy Min Kit (Thermoscientific, Lithuania). The quantity and quality were assessed by Beckman dual spectrophotometer (USA). SensiFAST ${ }^{\mathrm{T}}$ SYBR ${ }^{\circledR} \mathrm{Hi}-\mathrm{ROX}$ One-Step Kit, catalogue no. PI-50217 V had been formulated for highly reproducible first-strand cDNA synthesis and subsequent real-time PCR in a single tube in a 48-well plate using the step one instrument (Applied Biosystem, USA). Normalisation for variation in the expression of each target gene was performed referring to the mean critical threshold values of glyceraldehyde 3-phosphate dehydrogenase (GAPDH) housekeeping gene expression by the ${ }^{\Delta} \mathrm{Ct}$ method. Primers base sequences of the studied genes are listed in (Table 1).

\section{Assessment of TrX-1 by ELISA}

The amount of $\operatorname{TrX}-1$ was measured using Rat (TrX) ELISA kit, catalogue \#SRB-T-81639, Shanghai. The spectrophotometric absorbance was assessed at $450 \mathrm{~nm}$ in accordance with the manufacturer's instructions. The results were expressed as nmol per mg protein.

\section{Assessment of MDA and SOD by colorimetry}

The amount of MDA and activity of superoxide dismutase (SOD) were measured using colorimetry kit, Biodiagnostic, catalogue \#MD 2529, SD 2521 respectively in accordance with the manufacturer's instructions. The results were expressed as $\mathrm{nmol}$ per $\mathrm{g}$ protein and $U$ per $\mathrm{mg}$ protein.

\section{Processing of specimens and stains for light microscopy}

Tissue samples from left ventricle were fixed in buffered neutral formalin, processed through graded alcohols and xylene and embedded in paraffin blocks. Tissue sections of 4-6 $\mu \mathrm{m}$ were made at multiple levels. Sections were stained with haematoxylin and eosin (H\&E).

For Masson's trichrome stain, the samples were first deparaffinised and rehydrated, washed in distilled water then fixed and rinsed. Staining in Weigert's iron haematoxylin and Biebrichscarlet-acid fuchsin solution was done for $10 \mathrm{~min}$ for each stain with intervening rinsing. Differentiation in phosphomolybdic-phosphotungstic acid solution, staining with aniline blue solution, washing and dehydration were done before finally mounting with resinous mounting medium.

Immunohistochemistry for iNOS was performed on biopsies of deparaffinised rat cardiac tissue. Heat-induced antigen retrieval was performed using $10 \mathrm{mM}$ sodium citrate $(\mathrm{pH}$ 6.0) buffer and microwaved for 8-15 min for exposure of target proteins. Afterwards, tissues were blocked in 3\% BSA-PBS for 30 min at room temperature. Tissues were then probed at a dilution of 1:200 with a rabbit polyclonal antibody recognizing iNOS (ab3523, ABCAM, USA) or without primary antibody (negative control) overnight at $4{ }^{\circ} \mathrm{C}$ in a humidified chamber. Tissues were washed thoroughly with PBST and endogenous peroxidase activity was stopped by the addition of a peroxidase suppressor. Detection was performed using a biotin-conjugated secondary antibody and SA-HRP, followed by colorimetric detection using 3,30-diaminobenzidine (DAB). Tissues were counterstained with haematoxylin and prepped for mounting.

Immnunohistochemistry of PCNA entailed deparaffinisation and heating of paraffin-embedded heart sections in $0.01 \mathrm{M}$ sodium citrate buffer $(\mathrm{pH} \mathrm{6.0)}$ for 15 min followed by overnight incubation with rabbit 


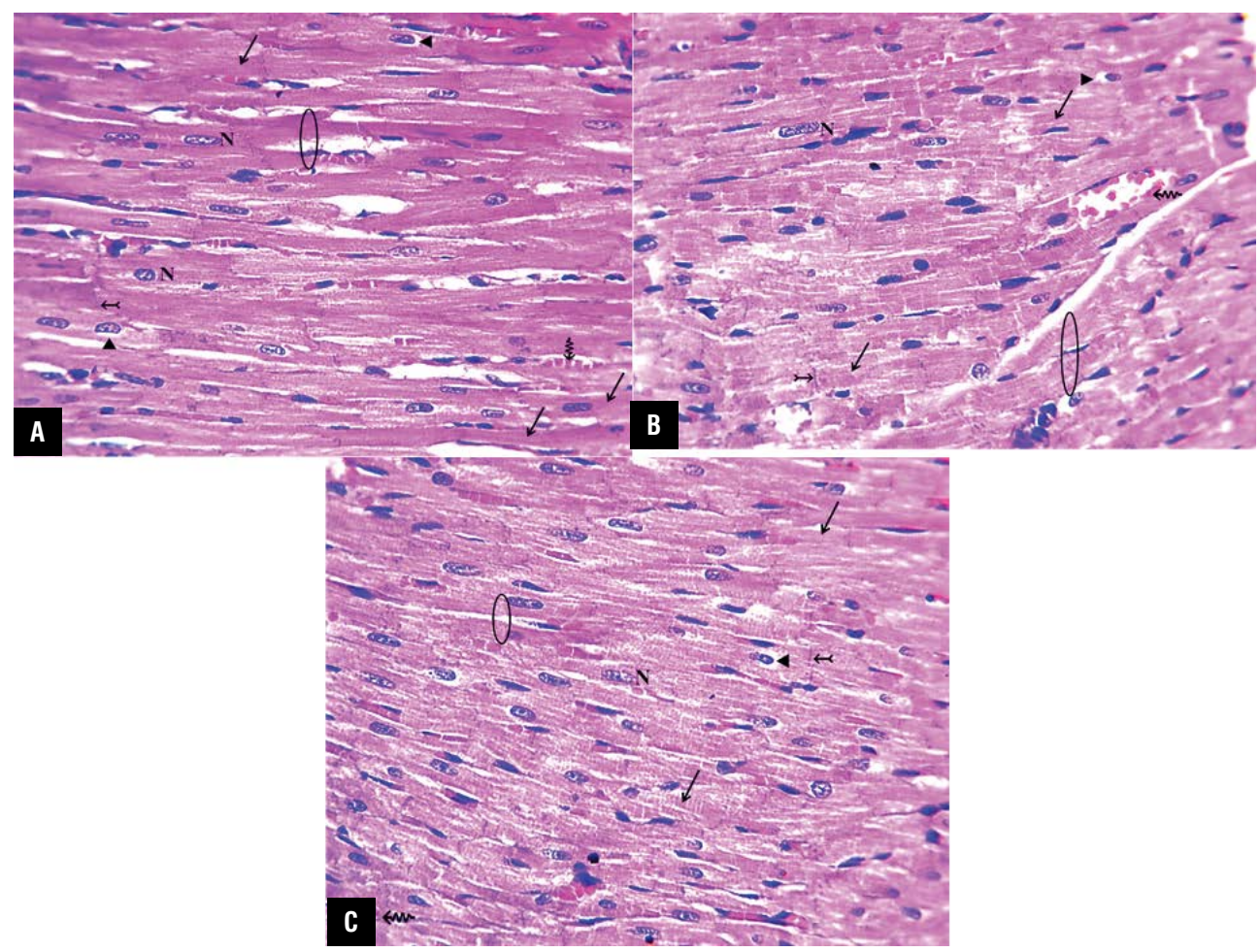

Figure 1. Haematoxylin and eosin (H\&E)-stained sections of control (A), vitamin $C$ sham control (B) and platelet-rich plasma (PRP) sham control (C) adult rat cardiac muscle exhibiting distinct cross-striations (arrows). Cardiac muscle fibres exhibit branching (circle) and one or two central vesicular nuclei (N) with perinuclear sarcoplasm (arrow heads). The terminal ends of adjacent cardiac muscle fibres reveal characteristic intercalated disks (tailed arrow). Narrow intercellular spaces with blood capillaries are seen (zigzag arrow). H\&E $\times 400$.

anti-PCNA antibodies (EPR382, ABCAM, USA) at $4^{\circ} \mathrm{C}$. $D A B$ was used as the chromogenic substrate and the sections were assessed by light microscopy. The characteristics and morphology of myocardial fibres for all previously mentioned stains were observed under a $400 \times$ magnification using a Leica DM 750 light field microscope and a Leica ICC50 HD camera.

\section{Statistical analysis}

Data were coded and entered using the GraphPad Prism version 7. Data was summarised using mean and standard deviation. Comparisons between groups were done using one way analysis of variance (ANOVA) with Tukey's multiple comparisons test when comparing more one variable in more than two groups.

\section{RESULTS}

\section{Histological results}

Haematoxylin and eosin-stained sections of the control and sham control groups showed normal histological architecture of heart cardiac muscle. The cardiac fibres exhibited cross-striations, branching and one or two central vesicular, open faced nuclei with surrounding perinuclear sarcoplasm. The terminal ends of adjacent cardiac muscle fibres revealed characteristic and dense-staining, end-to-end junctional complexes called intercalated disks (Fig. 1).

In the heart tissues of the Na fluoride group (IV), vascular dilatation and congestion were detected along with Zenker's degeneration of the myocardium. Loss of cross striations, fragmentation and separation of the fibres were also seen (Fig. 2). In the heart tissues of groups $\mathrm{V}$ and $\mathrm{VI}$, an apparent restoration of the normal architecture was featured in addition to mild hyperaemia at the myocardial interstitial intervals and in the capillaries (Fig. 3).

In Masson's trichrome-stained sections, the myocardial fibres were found to show a minimal positive reaction in groups I, II, III, V and VI, whereas a strong positive reaction was observed in group IV (Figs. 4, 5).

The immunohistochemical expressions of iNOS and PCNA in the cardiac tissue are shown in Figures 6 and 7, respectively. A weak expression was presented in the cardiac muscle of the control groups. However, iNOS and PCNA were significantly positively expressed in cardiac muscle, which presented as dark brown granules, in the NaF group. The apparent reduction 

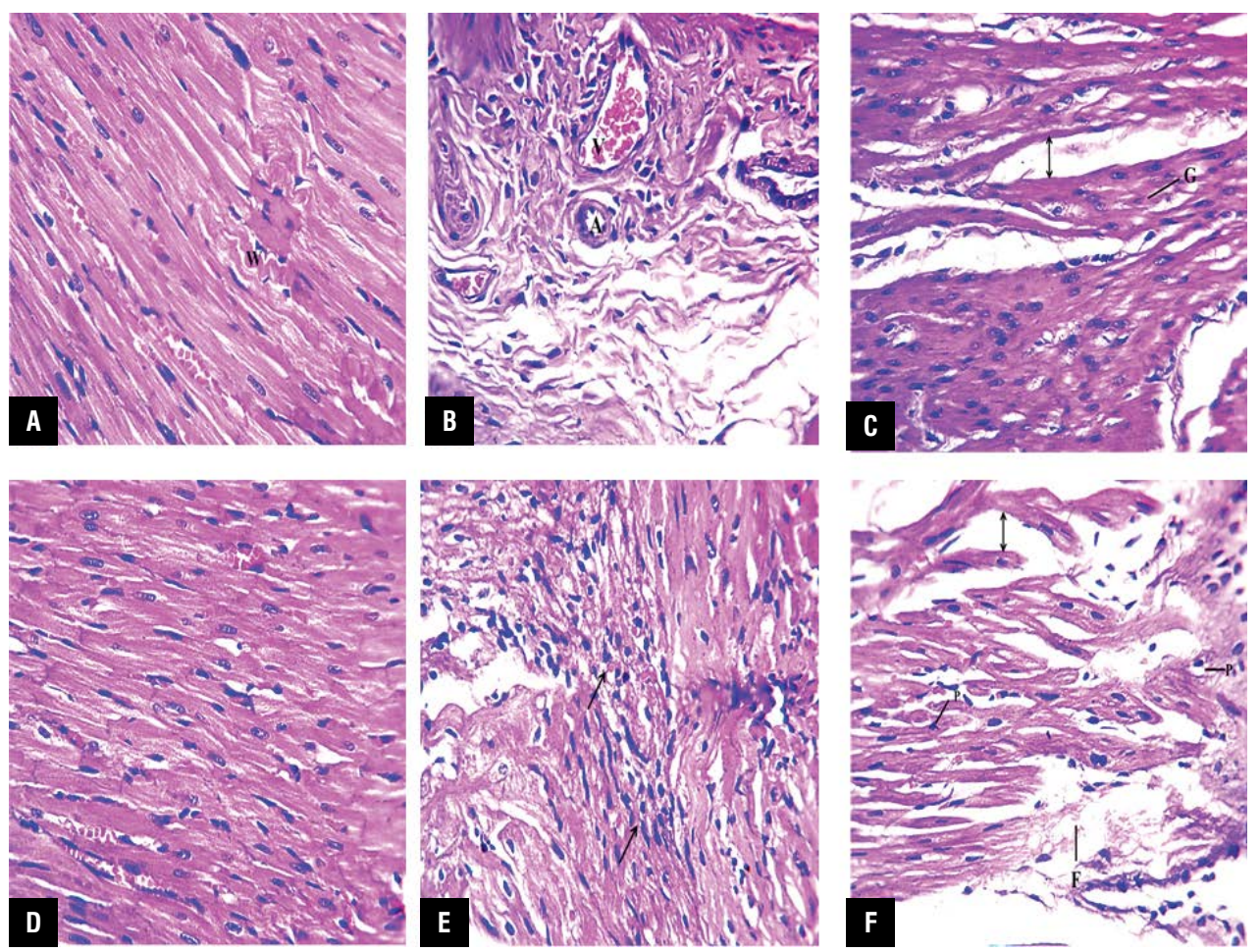

Figure 2. A-F. Haematoxylin and eosin (H\&E)-stained sections of sodium fluoride (NaF)-treated adult rat cardiac muscle, showing Zenker's degeneration with widely separated myocardial fibres (double arrow), loss of cross-striations and fragmentation (F). Some myocardial fibres exhibit a wavy orientation (W). Areas of normal histological architecture in panel $\mathbf{D}$ alternate with areas of loss of architecture in panel $\mathbf{B}$. Dilated and congested arteriole (A) and venule (V) are seen. Pyknotic nuclei (P) and ghost cells $(\mathrm{G})$ are noticeable along with areas of inflammatory cellular infiltration (arrows). $\mathrm{H} \& \mathrm{E} \times 400$.
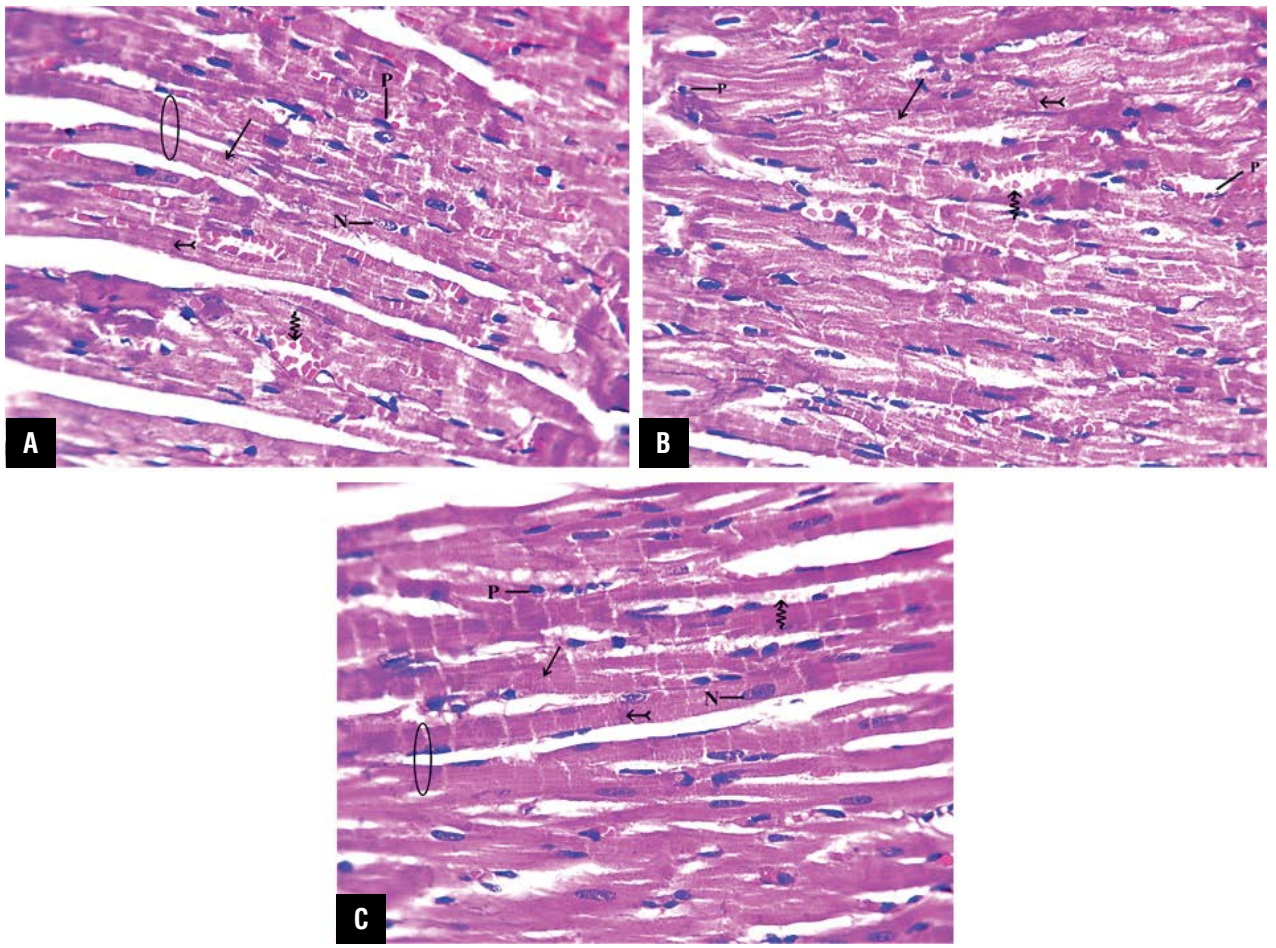

Figure 3. Haematoxylin and eosin (H\&E)-stained sections of panel A and B. Sodium fluoride (NaF) + vitamin C-treated; C. NaF + platelet-rich plasma-treated adult rat cardiac muscle exhibiting normalisation of histological architecture. Distinct cross-striations (arrows) are seen. Cardiac muscle fibres show branching (circle) and central vesicular nuclei (N) with persistence of some nuclear pyknosis (P). The terminal ends of adjacent cardiac muscle fibres show intercalated disks (tailed arrow). Intercellular spaces with blood capillaries are also seen (zigzag arrow). H\&E $\times 400$. 

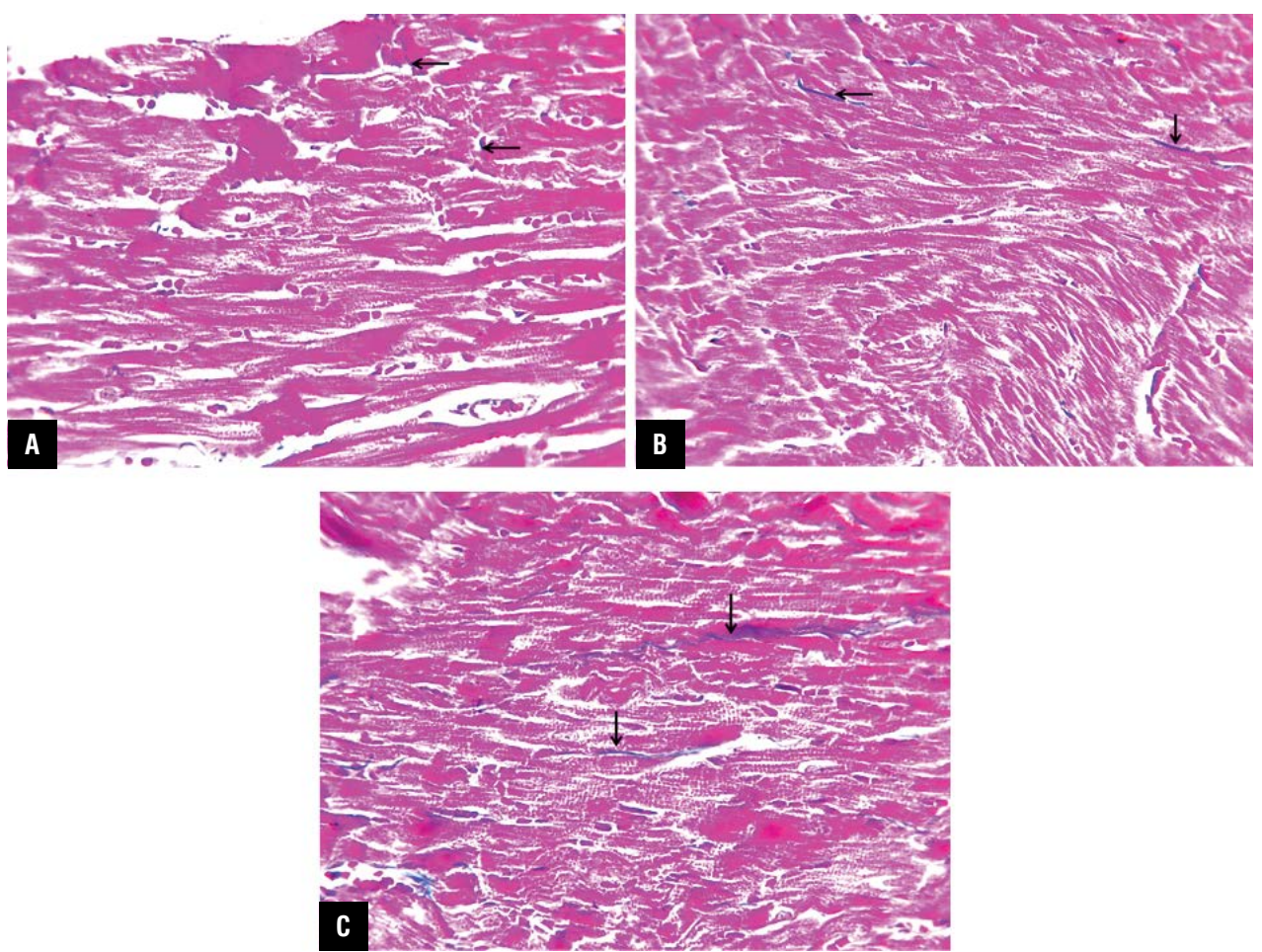

Figure 4. Masson's trichrome (MT)-stained panels of control (A), vitamin C sham control (B) and platelet-rich plasma sham control (C) adult rat cardiac muscle exhibiting positive reaction (arrows). Blue colour indicates positivity. MT $\times 400$.
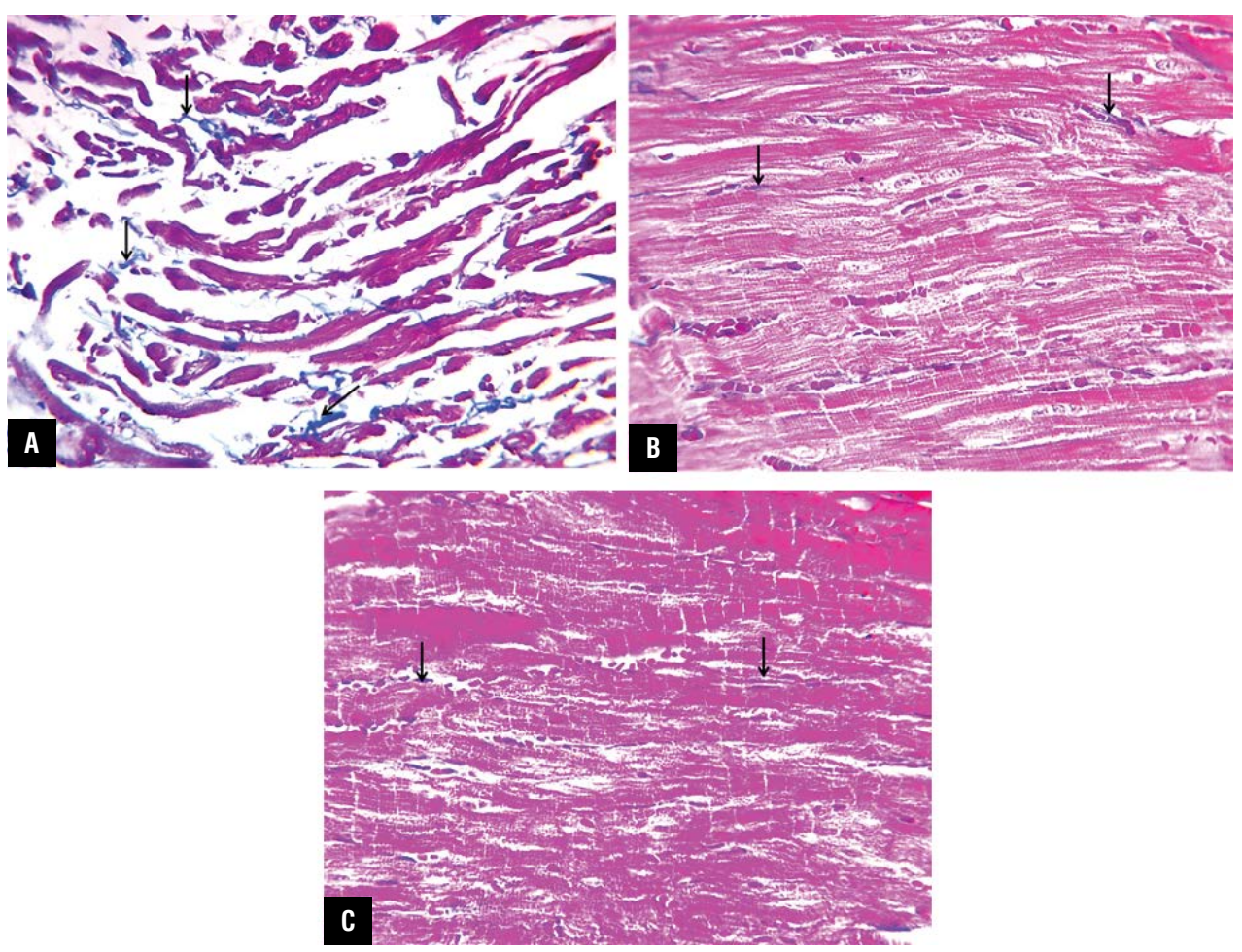

Figure 5. Masson's trichrome (MT)-stained sections of sodium fluoride (NaF)-treated adult rat cardiac muscle exhibiting a strong positive reaction (arrows) (A), $\mathrm{NaF}+$ vitamin C-treated $(\mathbf{B})$ and $\mathrm{NaF}+$ platelet-rich plasma-treated adult rat cardiac muscle exhibiting positive reaction (arrows) (C). Blue colour indicates positivity. MT $\times 400$. 

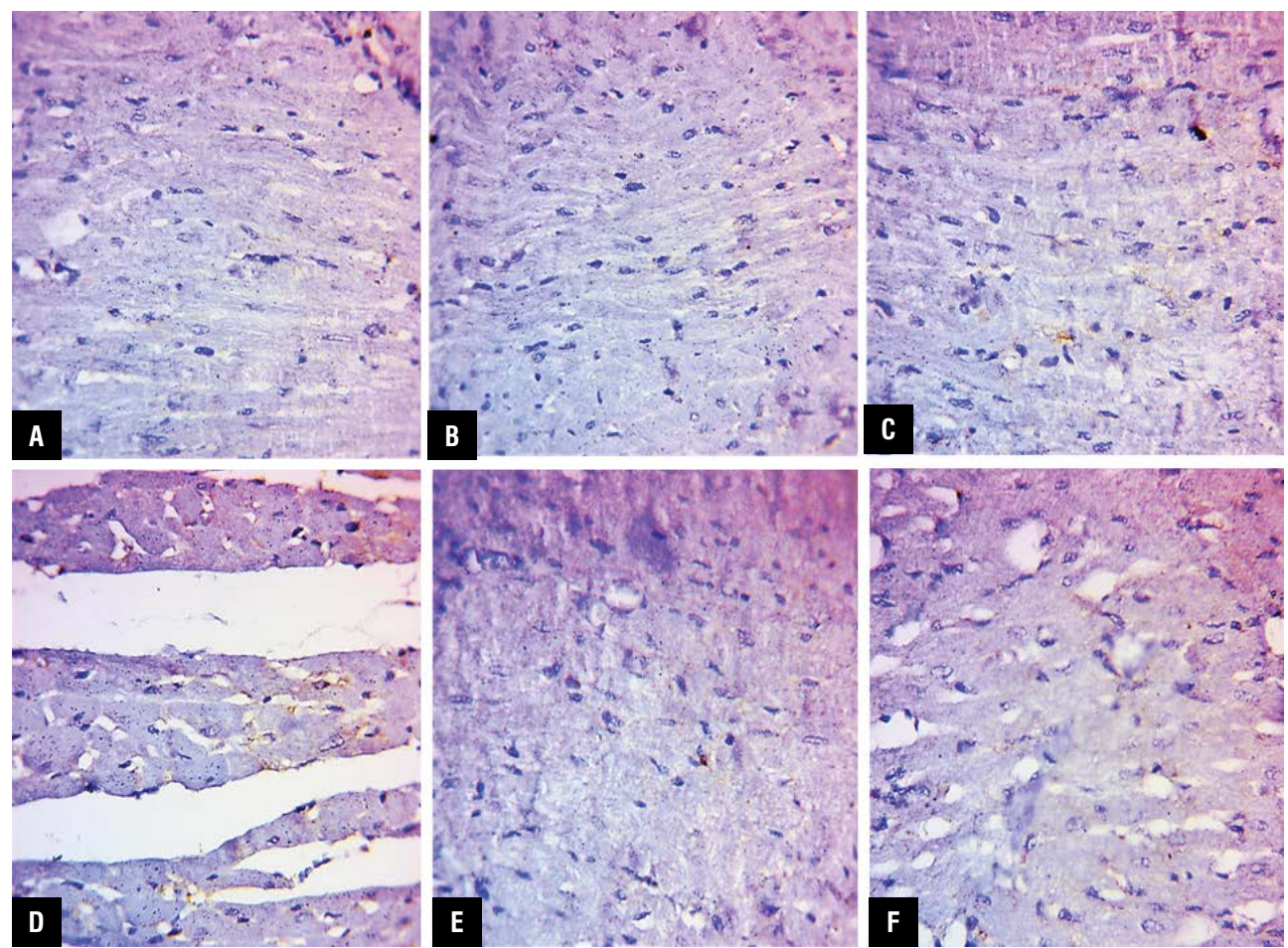

Figure 6. Inducible nitric oxide synthases (iNOS) immunohistochemistry of adult rat cardiac muscle in control (A), vitamin C sham control (B) and platelet-rich plasma (PRP) sham control exhibiting minimal iNOS-immunopositivity (C). D. Apparent increase in iNOS-immunopositivity in sodium fluoride (NaF)-treated rat myocardium. Minimal iNOS expression in panel E. NaF + vitamin C-treated and NaF + PRP-treated rats (F). Brown colour indicates positivity. iNOS immunohistochemistry, haematoxylin counterstain $\times 400$.
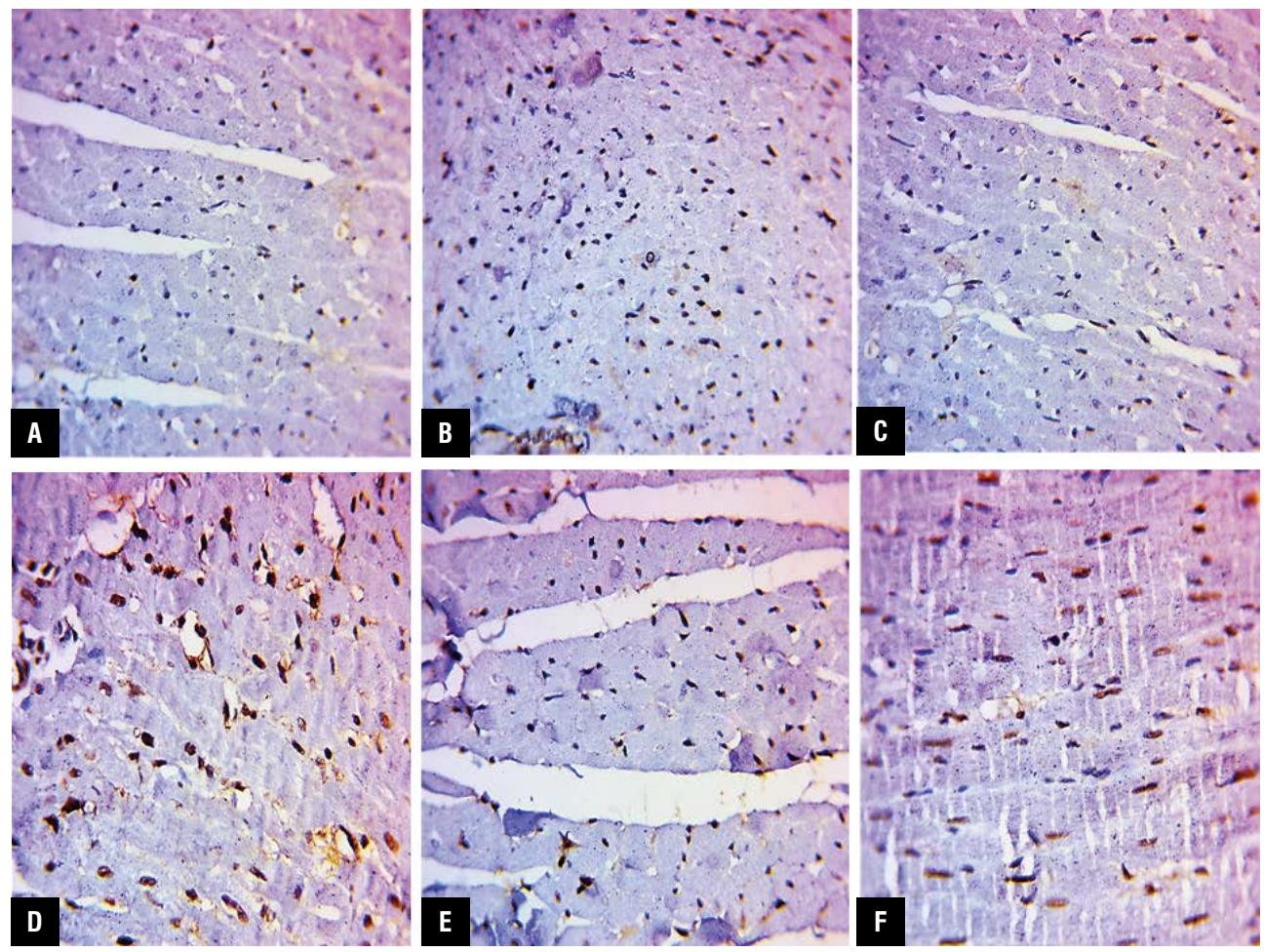

Figure 7. Proliferating cell nuclear antigen (PCNA) immunohistochemistry of adult rat cardiac muscle in control (A), vitamin $C$ sham control (B) and platelet-rich plasma (PRP) sham control exhibiting minimal PCNA-immunopositivity (C). D. Apparent increase in PCNA-immunopositivity in sodium fluoride ( $\mathrm{NaF}$ )-treated rat myocardium. Minimal PCNA expression in panel $\mathbf{E}$. NaF + vitamin C-treated and moderate expression in panel F. NaF + PRP group. Brown colour indicates positivity. PCNA immunohistochemistry, $\times 400$. 
Table 2. Multiple comparisons of $p$ values for Masson's trichro$m e$, inducible nitric oxide synthases (iNOS) and proliferating cell nuclear antigen (PCNA) expression between the different experimental groups

\begin{tabular}{ll}
\hline Group & P \\
\hline Masson's trichrome & \\
Control vs. sham control & 1.000 \\
NaF-treated & 0.000 \\
Vitamin C & 0.002 \\
PRP-treated & 0.031 \\
NaF vs. sham control & 0.000 \\
Vitamin C & 0.000 \\
PRP-treated & 0.022 \\
PRP vs. sham control & 0.029 \\
Vitamin C & 1.000 \\
Vitamin C vs. sham control & 0.000 \\
iNOS & \\
Control vs. sham control & 1.000 \\
NaF-treated & 0.000 \\
Vitamin C & 0.000 \\
PRP-treated & 0.019 \\
NaF vs. sham control & 0.000 \\
Vitamin C & 0.000 \\
PRP-treated & 0.000 \\
PRP vs. sham control & 0.029 \\
Vitamin C & 1.000 \\
Vitamin C vs. sham control & 0.000 \\
PCNA & \\
Control vs. sham control & 1.000 \\
NaF-treated & 0.000 \\
Vitamin C & 0.000 \\
PRP-treated & 0.000 \\
NaF vs. sham control & 0.000 \\
Vitamin C & 0.000 \\
PRP-treated & 0.000 \\
PRP vs. sham control & 0.000 \\
Vitamin C & 1.000 \\
Vitamin C vs. sham control & 0.000 \\
\hline P 00 is cosided & \\
\hline
\end{tabular}

$\mathrm{P}<0.05$ is considered significant. NaF — sodium fluoride; PRP — platelet-rich plasma

in PCNA immunopositivity in group $\mathrm{VI}$ was not as marked as that of group $\mathrm{V}$.

The relative densities of Masson's trichrome, iNOS and PCNA in the myocardium of the NaF group was also significantly higher $(p<0.05)$ than the control group and lower $(p<0.05)$ in the vitamin C and PRP groups than the NaF group (Tables 2,3).

\section{Biochemical and molecular results Oxidative markers}

MDA level in $\mathbf{n m o l} / \mathbf{g}$ tissue. A statistically significant difference was seen in MDA level between the different study groups ( $p<0.0001)$. MDA level in the NaF-treated group $(14 \pm 0.46)$ was significantly increased compared to the control group (1.3 \pm $\pm 0.13 ; p<0.0001)$. In the vitamin C and PRP-treated groups, significant reductions in MDA level (4.1 \pm \pm 0.52 and $8.1 \pm 0.28$ with $p<0.0001$ and $p=0.0003$, respectively) were observed when compared to the NaF-treated group. In addition, there was a statistically significant decrease in MDA level in the vitamin $C$ group compared to PRP group ( $p=0.0017$ ) (Fig. 8A).

SOD level in $\mathrm{U} / \mathrm{g}$ tissue. A statistically significant difference was seen in SOD level between the different study groups $(p=0.03)$. SOD level in NaF-treated group ( $2.9 \pm 0.05)$ was significantly decreased compared to the control group $(4.0 \pm 0.37 ; p=0.033)$. In the vitamin $C$ and PRP-treated groups, a non-significant increase in SOD level $(3.8 \pm 0.16$ and $3.3 \pm$ \pm 0.27 with $p=0.067$ and $p=0.37$, respectively) were observed when compared with the NaF-treated group. In addition, there was no statistically significant difference in SOD level in the vitamin $C$ group when compared with PRP group ( $p=0.37$ ) (Fig. 8B).

TrX-1 level in $\mathbf{n g} / \mathbf{g}$ tissue. There was no statistically significant difference in $\mathrm{TrX}-1$ level among the different study groups ( $p=0.23$ ). Its level in the control group was $21 \pm 0.7$ compared to $15 \pm 0.56$ in NaF-treated group. TrX-1 level in the vitamin C and PRP-treated groups was $23 \pm 3.3$ and $30 \pm 11$, respectively (Fig. $8 \mathrm{C}$ ).

Table 3. Mean \pm standard deviation for Masson's trichrome, inducible nitric oxide synthases (iNOS) and proliferating cell nuclear antigen (PCNA) expression between the different experimental groups

\begin{tabular}{lccc}
\hline Groups & Masson's trichrome & iNOS & PCNA \\
\hline Control & $1.183 \pm 0.123$ & $1.851 \pm 0.064$ & $70 \pm 0.44$ \\
Sham control & $1.191 \pm 0.91$ & $1.924 \pm 1.09$ & $76 \pm 0.53$ \\
NaF-treated & $16.371 \pm 1.171+$ & $19.176 \pm 3.327+$ & $874 \pm 1.09+$ \\
Vitamin C-treated & $1.505 \pm 0.423+^{*}$ & $8.924 \pm 0.486+^{*}$ & $132 \pm 0.411+^{*}$ \\
PRP-treated & $6.682 \pm 1.401+^{*}$ & $12.326 \pm 0.98+^{*}$ & $352 \pm 0.82+^{*}$ \\
\hline
\end{tabular}

Data are shown as mean \pm standard deviation; $+p<0.05$, significant difference compared to that of the control group; ${ }^{*} p<0.05$, significant difference compared to that of the NaF-treated group; $\mathrm{NaF}$ — sodium fluoride; PRP — platelet-rich plasma 
A

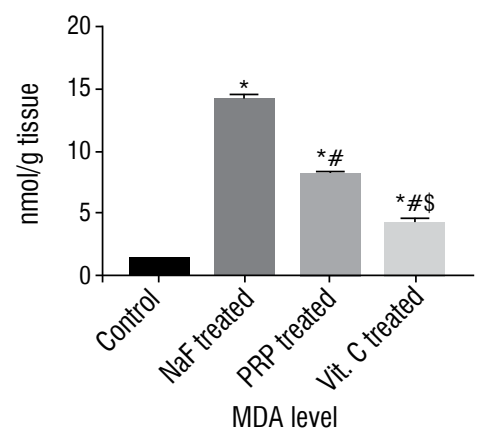

D

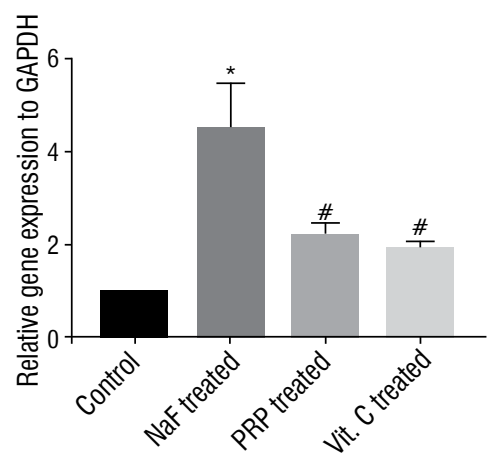

Keap1 gene expression
B
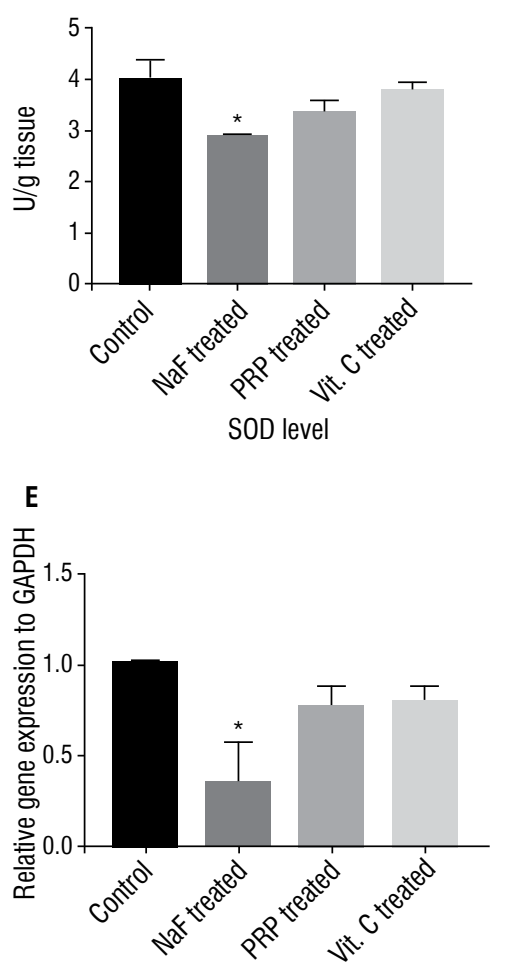

Nrf2 gene expression
C
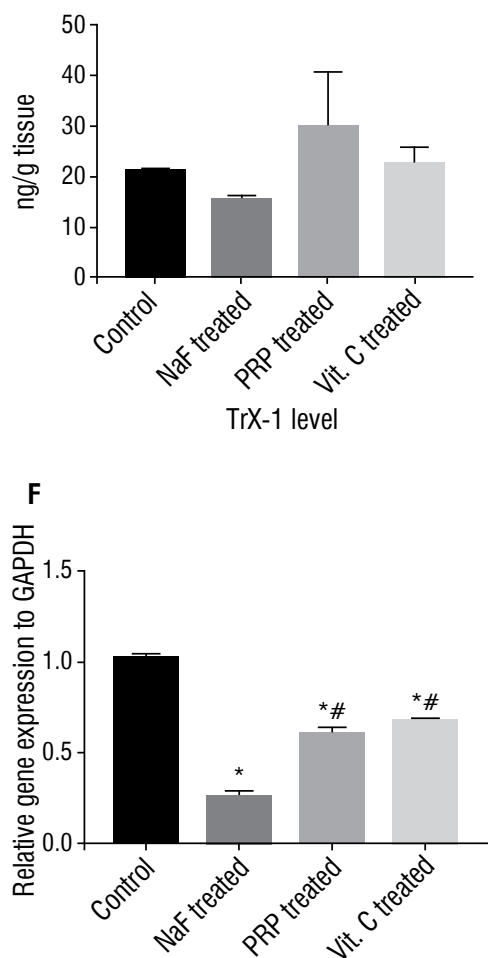

H0-1 gene expression

Figure 8. A-F. Different levels of biochemical and molecular markers. Data were expressed as mean \pm standard deviation, $p$ value $<0.05$ was significant; * significant difference vs. control group; \#significant difference vs. sodium fluoride (NaF)-treated group; $\$$ significant difference vs. platelet-rich plasma (PRP)-treated group; MDA — malondialdehyde; SOD — superoxide dismutase; TrX-1 — thioredoxin-1 oxidoreductase; Vit. — vitamin; GAPDH — glyceraldehyde 3-phosphate dehydrogenase.

\section{Gene expression}

\section{Keap1}

A statistically significant difference was seen in Keap1 gene expression among the different study groups $(p=0.01)$. Keap1 gene expression in NaF-treated group $(4.5 \pm 0.99)$ was significantly increased compared to control group ( $1 \pm 0.007 ; p=0.0008)$. In the vitamin $\mathrm{C}$ and PRP-treated groups, significant reductions in Keap1 gene expression $(1.9 \pm 0.16$ and $2.2 \pm 0.28$ with $p<0.025$ and 0.03 , respectively) were observed when compared to the NaF-treated group. In addition, there was no a statistically significant difference in Keap1 gene expression in the vitamin $C$ group compared to PRP group ( $p=0.93$ ) (Fig. 8D).

\section{Nrf2}

A statistically significant difference was seen in Nrf2 gene expression among the different study groups $(p=0.032)$. Nrf2 gene expression in NaF-treated group $(0.35 \pm 0.03)$ was significantly decreased compared to the control group $(1 \pm 0.014 ; p=0.026)$. In the vitamin C and PRP-treated groups, there was no a statistically significant difference between the $\operatorname{PRP}(7.7 \pm 0.11)$ and vitamin C $(0.8 \pm 0.11)$ pretreated groups compared with NaF-treated group ( $p=0.1$ and $p=0.08$, respectively). In addition, there was non-significant difference in Keap1 gene expression in the vitamin C group compared to PRP group $(p=0.99)$ (Fig. 8E).

\section{HO-1}

A statistically significant difference was seen in HO-1 gene expression among the different study groups $(p<0.0001)$. HO-1 gene expression in NaF-treated group $(0.26 \pm 0.03)$ was significantly decreased compared to the control group $(1 \pm 0.02)$ $(p<0.0001)$. In the vitamin C and PRP-treated groups, significant difference in HO-1 gene expression $(0.68 \pm 0.02$ and $0.61 \pm 0.03$ with $p=0.001$ and $p=0.0005$, respectively) were observed when compared to the control group. A statistically significant increase in HO-1 gene expression in PRP and vitamin C groups was seen when compared to $\mathrm{NaF}$ treated group ( $p=0.0005$ and $p=0.001$, respectively) (Fig. 8F). 


\section{Statistical results}

Statistical results for Masson's trichrome optical density and iNOS and PCNA immunohistochemical expression are shown in Table 2 and Table 3. Masson's trichrome's optical density of the NaF-intoxicated group (16.371 \pm 1.171$)$ significantly increased compared to the control $(1.183 \pm 0.123)$ and the sham control $(1.191 \pm 0.91)$ groups. The groups that were pretreated with vitamin C and PRP prior to $\mathrm{NaF}$ intoxication showed a significant reduction in optical density $(1.505 \pm 0.423$ and $6.682 \pm 1.401$, respectively) when compared to the NaF group. Pretreatment with vitamin $C(8.924 \pm 0.486)$ and PRP $(12.326 \pm 0.98)$ significantly lowered the immunoexpression of iNOS when compared to the NaF group (19.176 \pm 3.327$)$, while the expression of the latter was significantly increased in comparison to the control $(1.851 \pm 0.064)$ and sham control (1.924 \pm 1.09$)$ groups. Intoxication with $\mathrm{NaF}$ caused a significant increase in PCNA immunoexpression (874 \pm 1.09) when compared to the control $(70 \pm 0.44)$ and sham control (76 \pm 0.53$)$ groups. Vitamin C (132 \pm 0.411$)$ and PRP (352 \pm 0.82$)$ PCNA expression were decreased when compared to the NaF group. A statistically significant difference between the vitamin $C$ and PRP-pretreated groups and the control groups was seen in all measured parameters.

\section{DISCUSSION}

Sodium fluoride toxicity continues to be a major health problem worldwide. In the current study, myocardial damage was induced in rats by oral ingestion of NaF. The purpose of our study was to evaluate the potential cardio protective role of vitamin C and PRP in NaF-induced cardiac toxicity in rat model. This was performed with reference to biochemical, molecular, immunohistochemical and histopathological changes.

Zhao et al. [52] suggested that DNA replication is an indicator of cellular proliferation. The authors also stated that DNA replication is lowered, because of the synthesis of PCNA, in inactive cells but varies according to the phase of the cell cycle, making PCNA expression a marker of cellular proliferation. In the present study, PCNA expression in the cardiac muscle was assayed by immunohistochemistry. In agreement with our results, Zhao et al. [52] observed a weak PCNA expression in the control group, and a significant positive PCNA expression in the fluoride-administered group of adult male rats' testes. They concluded that spermatogenesis dysfunction and damage of tissue ultrastructure was caused by fluoride-induced apoptosis to which the positive PCNA expression was related, since according to the authors, apoptosis is associated with proliferation. Although previous studies have pointed out a reduction in cellular proliferation in response to fluoride exposure, the authors mentioned that cell proliferation could be maintained through the overexpression of PCNA as a response to fluoride-induced cellular apoptosis.

Shenoy et al. [42] assessed the effect of NaF administration at different concentrations on myoblast proliferation. In contrast our study where $\mathrm{NaF}$ was administered at a dose of $25 \mathrm{mg} / \mathrm{kg}$, the author concluded that at a low concentration of 1.5 ppm (1 ppm being equivalent to $1 \mathrm{mg} / \mathrm{kg}$ ), NaF administration resulted in myoblast proliferation and myotubular hypertrophy via an IGF-1/AKT pathway activation, whereas at a higher concentration of 5 ppm, NaF caused myotubular atrophy via an ubiquitin-proteosome pathway. Enhancement of skeletal muscle catabolism, production of reactive oxygen species (ROS) and inflammatory cytokines were also reported by the authors when higher concentrations of $\mathrm{NaF}$ were administered. As regards apoptosis, the authors recorded that via PI3K/Akt signalling, NaF was capable of induction of apoptosis and reduction in cell viability when administered in a dose higher than 40 ppm.

Luo et al. [26] investigated the underlying molecular mechanism of NaF-induced cytotoxicity and cell-cycle alterations in renal cells. In contrast to the present study, the authors reported that at more than $12 \mathrm{mg} / \mathrm{kg}$ body weight, a NaF-induced G2/M phase cell-cycle arrest was seen, leading to a significant increase in cell percentage present in the G2/M phase. According to the authors, the cycle arrest occurred by activating the ATM-Chk2-p53/Cdc25C signalling pathway which inhibited cellular proliferation and was associated with down regulation of PCNA mRNA expression.

In the present study, an increase in collagen fibres deposition was seen in the NaF group, as assayed by Masson's trichrome staining and image analysis. Chen et al. [7] investigated the role of tumour necrosis factor-like weak inducer of apoptosis (TWEAK)/fibroblast growth factor-inducible molecule 14 (Fn14) axis in myocardial fibrosis. The authors observed that stimulation of rat cardiac fibroblasts (CFs) with TWEAK increased CFs numbers and collagen synthesis via activation of the nuclear factor-kappaB (NF- $\kappa \mathrm{B})$ pathway 
and a subsequent production of metalloproteinase- 9 (MMP-9). The authors emphasized the importance of the TWEAK/Fn 14 axis in control of myocardial fibrosis.

In contrast to the NaF-induced collagen deposition seen in the current study, Gupta et al. [17] detected that fluoride disturbs collagen synthesis causing the cells responsible for its synthesis to produce larger amounts of under-hydroxylated, inadequately cross-linked and rapidly catabolised collagen and/or non-collagenous proteins as a compensation. The net result is a decrease in the collagen content of tissues.

In the present study a statistically significant increase in NaF-induced iNOs expression was observed. In line with the observations of this study, Oyagbemi et al. [35] reported an increase in oxidative stress markers in cardiac tissue, in response to $\mathrm{NaF}$ administration. The latter authors recorded abnormalities in the histological architecture of the heart tissue and an increase in NF- $\mathrm{kB}$ expression as assayed by immunohistochemistry. The authors indicated that NaF-induced alterations were achieved through generation of reactive oxygen species and activation of cardiac $\mathrm{NF}-\mathrm{\kappa B}$ expression, oxidative stress being an activator of NF- $\mathrm{KB}$. The authors mentioned that activation of NF- $\kappa B$ results in its release from cytosolic inhibitors and its translocation to the nucleus and consequently to the expression of NF-kB-target genes causing tissue inflammation and damage.

The mechanism of NaF-induced oxidative stress was explained by Gupta et al. [18]. The authors reported that fluoride causes a respiratory burst and oxygen free radicals production. The authors stated that hydroxyl radicals and superoxide radicals prevail at low and high concentrations of fluoride. The authors attributed the fluoride-induced oxidative stress to its ability to cause mitochondrial swelling and disruption and alteration of enzymes of cellular respiration. The net result is a decrease in adenosine triphosphate concentration, which in turn induces production of hydrogen peroxide and reactive oxygen species.

The current investigation revealed an increase in NaF-induced iNOs expression. He et al. [20] examined the possible effect of fluoride exposure on the expression of nitric oxide (NO) and iNOS on cultured chondrocytes. The authors stated that production of NO can be under control of iNOS and that both low and high levels of $\mathrm{F}$ - significantly increased the activity of iNOS and consequently the level of NO leading to oxidative tissue damage.
Ngoc et al. [34] investigated the manner of NaF-induced cell death and the mechanisms involved, where they found that it occurs mainly by apoptosis rather than necrosis. The authors reported that administration of more than $1 \mathrm{mMNaF}$ leads to apoptosis through hydroxyl radical-dependent and caspase- and JNK mediated pathways. According to the authors, GADD45 $\alpha$ plays a crucial role in the induction of apoptosis, in which its transcription and function are controlled either by JNK1 or JNK2. NaF administration stimulated the induction of GADD $45 \alpha$, whereas a JNK specific inhibitor inhibited such effect. The authors also reported that ROS are normally produced at low concentrations in a constant manner in living organisms, serving the function of immune cells. However, over-expression or decreased removal of intracellular ROS induces oxidative damage to cells and tissues. The authors mentioned that through an elevation of oxidative stress-mediated lipid peroxidation and subsequent mitochondrial stress, that fluoride induces apoptosis. They suggested that ROS are mediators of NaF-mediated apoptosis, where mitochondrial stress is at least in part involved. The authors concluded that the mitochondrial- and caspase-mediated signalling accompanied by intracellular ROS accumulation is involved in NaF-induced apoptosis. The authors also concluded that JNK-GADD45 $\alpha$ - and p53-mediated signalling is critical for NaF-mediated apoptosis, where ROS act as the most crucial upstream mediator.

In agreement with the histological results of the current work, Oyagbemi et al. [35] reported an infiltration of the myocardial interstistium by inflammatory cells in response to $\mathrm{NaF}$ treatment. Yildirim et al. [49] investigated the effect of $\mathrm{NaF}$ on cardiac histopathology. The investigation revealed hyperaemia of interstitial vessels, hyaline degeneration and Zenker's necrosis in muscle fibres and mononuclear cell. A study done by Basha and Sujitha [5] recorded myocarditis with cloudy swelling, necrosis, haemorrhage, inflammation, and atherosclerosis in cardiac tissue with chronic fluorosis. Another experimental fluorosis study done by Al Shahat and Naggar [2] revealed capillary congestion, mononuclear cell infiltration and haemorrhage in the myofibrillar interval, severe muscle degeneration, and cytoplasmic vacuolisation. In our study, the NaF group revealed Zenker's degeneration with wide separation of myocardial fibres, loss of cross-striations and fragmentation. Dilatation and congestion of blood vessels, nuclear 
pyknosis and inflammatory cellular infiltration were also noticeable.

The heart is vulnerable to oxidative stress due to the abundance of mitochondria; the site of basal ROS generation and due to its inherent low antioxidant defences [51]. Vitamin $\mathrm{C}$ is an electron donor, and this is the basis of all its known functions. It is a soluble antioxidant that prevents oxidative damage by eliminating free radicals [36]. In the present study, vitamin C significantly ameliorated the NaF-induced alterations seen in rats' myocardium.

The results of Ghosh et al. [14] suggest that vitamin $C$ is capable of intracellular antioxidant enzymes restoration and maintenance of endogenous antioxidant molecules' levels, leading the authors to include it as a positive control to verify the experimental set up against NaF-induced oxidative stress and cell death.

Sirtuin 1 (Sirt1), which is a NAD-dependent class III histone deacetylase, plays a fundamental role in multiple cellular processes via deacetylation. It controls mitochondrial health by limiting the generation of mitochondrial-derived ROS (mROS). Sirt1 deacetylases manganese superoxide dismutase (SOD2); a key enzyme involved in regulating mROS production, consequently increasing SOD2 activity [48]. Low levels of Sirt1 are associated with increased mROS levels [38]. Liu et al. [25] mentioned that Sirt1 expression has antioxidant regulatory effects in cardiac tissue where it regulates antioxidant systems.

Peng et al. [37] investigated the beneficial effects of vitamin $\mathrm{C}$ against NaF-induced cytotoxicity and the underlying molecular mechanisms. The authors found that NaF caused cytotoxicity, stimulated mROS production, and prompted apoptosis in $\mathrm{F} 9$ embryonic carcinoma cells. NaF administration was also accompanied with decreased Sirt1 protein expression. They found that NaF-induced mitochondrial oxidative injuries were significantly attenuated by overexpression of Sirt1 or incubation with Mito-TEMPO (a SOD2 mimetic). The authors reported that pretreatment with vitamin $C$ enhanced the expression of Sirt1 and decreased NaF-induced mitochondrial oxidative stress and apoptosis. The authors confirmed that vitamin C-induced reduction in mROS and apoptosis was blocked by a knockdown of Sirt1 by means of inhibiting Sirt1-SOD2 signalling. They also reported that sodium-dependent vitamin C transporter 2 (SVCT-2) siRNA was capable of hindering the capacity of vita$\min C$ to stimulate Sirt1/SOD2 signalling.
Zaki et al. [51] revealed that the modulatory effect of mesenchymal stem cells (MSCs) pretreated with PRP on doxorubicin (DOX)-induced cardiotoxicity was superior to the modulatory effect of MSCs alone. The authors mentioned that oxidative stress underlies the DOX-induced cardiotoxicity and accordingly found the oxidant marker MDA to be elevated, while the antioxidant marker SOD decreased in DOX-treated groups. A significant improvement of both markers in the MSC- and PRP/MSC-treated groups was seen with a significant MDA difference in favour of PRP/MSC-treated group. A 100\% higher Bcl2/Bax ratio was seen after MSCs were pretreated with PRP when apoptosis was assessed. In line with the present results, PRP showed a similar preventive role like vitamin C.

In the cardiovascular system, important antioxidative molecules are catalase, SOD, glutathione, glutathione S-transferases, glutathione peroxidases, haem oxygenases, thioredoxin reductases, and thioredoxins. The expression of those antioxidative molecules can be regulated by the transcription factor nuclear factor erythroid 2-related factor 2 [22].

The potential antioxidant properties of PRP and vitamin $\mathrm{C}$ to antagonise cardiac toxicity of $\mathrm{NaF}$ were studied in the current experiment. Their antioxidant potential was investigated through their effect on the Keap1/Nrf2/HO-1 as a redox signalling pathway. In the current study, the cardiac toxicity with $\mathrm{NaF}$ caused the depletion of SOD, TrX-1 and increase in MDA level and increase in Keap1 levels, and it decreased Nrf2 and HO-1 mRNA expressions levels, which are markers of oxidative stress. Many studies demonstrated that $\mathrm{NaF}$ administration reduces the activity of mitochondrial antioxidant enzymes leading to cardiotoxicity, finally resulting in myocardial necrosis [9]. Activation of Nrf2 is done to antagonise reactive oxidants, while decreased Nrf2 activity has the opposite action [43]. The treatment of tumour cells with vitamin $\mathrm{C}$ reduced the expression of Nrf2 at the mRNA and protein levels [32]. These are studies agreed with our study, PRP and vitamin $C$ reduced Keap1 expression and increased the nuclear accumulation of Nrf2, which is associated with higher expression levels of HO-1, SOD, and mitochondrial antioxidant enzymes. These results are agreed with earlier studies suggesting PRP and vitamin $C$ as an anti-oxidative stress agent [19, 23]. Lawal et al. [24] investigated the antioxidant efficacy of heated garlic juice (HGJ) in liver against ascorbic acid (AA) in rats exposed to cadmium. Their results 
showed that AA was a more effective antioxidant than HGJ in avoiding cadmium-induced oxidative damage in liver and its action intervened through Nrf2-Keap1 pathway. Saif-Elnasr et al. [41] studied the treatment of hepatotoxicity induced by $\gamma$-radiation in albino rats by PRP and/or LMC. Their study revealed that treatment with PRP and/or LMC decrease hepatic MDA levels and increase Nrf2 levels. Another report proposed that vitamin $C$ reduced the levels of the oxidants MDA in acute and regular exercise [40]. The present study proved that PRP and vitamin $\mathrm{C}$ can be used a cardio-protective agent in NaF toxicity, which is possibly associated with the modulation of the Keap1/ /Nrf2 pathway, stimulating the nuclear accumulation of Nrf2 and the upregulation of phase II antioxidant enzyme expression such as HO-1, SOD, and TrX-1.

\section{CONCLUSIONS}

The presented results suggest that pretreatment with vitamin $C$ and PRP possess a potential cardio-protective effect against $\mathrm{NaF}$ intoxication in adult male albino rats. This study is the first to show that the cardio-protective effect of PRP, against NaF intoxication in the homogenates of rat heart tissues is comparable to that of vitamin $\mathrm{C}$ and might be considered for clinical trials. The results can be viewed as a starting point for further applications of this natural compound in the pharmaceutical industry after performing clinical researches. Our data illustrates a new molecular mechanism underlying the ability of vitamin C and PRP to be explored for future treatment of NaF-induced cytotoxicity.

\section{Conflict of interest: None declared}

\section{REFERENCES}

1. Ago T, Yeh I, Yamamoto $M$, et al. Thioredoxin1 upregulates mitochondrial proteins related to oxidative phosphorylation and TCA cycle in the heart. Antioxid Redox Signal. 2006; 8(9-10): 1635-1650, doi: 10.1089/ars.2006.8.1635, indexed in Pubmed: 16987018.

2. Al Shahat AA, Naggar A. Possible protective role of calcium against fluoride induced cardio toxicities in adult male albino rats. J Am Sci. 2013; 9(4): 1-5, doi: 10.7537/ marsjas090413.01.

3. Araujo JA, Zhang M, Yin F. Heme oxygenase-1, oxidation, inflammation, and atherosclerosis. Front Pharmacol. 2012; 3: 119, doi: 10.3389/fphar.2012.00119, indexed in Pubmed: 22833723.

4. Hammett-Stabler CA. Disposition of toxic drugs and chemicals in man. RC Baselt. Foster City, CA: Chemical Toxicology Institute. 1999; 90, doi: 10.1093/clinchem/46.6.889a.
5. Basha MP, Sujitha NS. Chronic fluoride toxicity and myocardial damage: antioxidant offered protection in second generation rats. Toxicol Int. 2011; 18(2): 99-104, doi: 10.4103/0971-6580.84260, indexed in Pubmed: 21976813.

6. Bielecki T, Dohan Ehrenfest DM, Everts PA, et al. The role of leukocytes from L-PRP/L-PRF in wound healing and immune defense: new perspectives. Curr Pharm Biotechnol. 2012; 13(7): 1153-1162, doi: 10.2174/138920112800624373, indexed in Pubmed: 21740376.

7. Chen HN, Wang DJ, Ren MY, et al. TWEAK/Fn14 promotes the proliferation and collagen synthesis of rat cardiac fibroblasts via the NF-кB pathway. Mol Biol Rep. 2012; 39(8): 8231-8241, doi: 10.1007/s11033-012-1671-3, indexed in Pubmed: 22555979.

8. Chinoy NJ. Effects of fluoride on physiology of animals and human beings. Indian J Environ Toxicol. 1991; 1(1): 17-32.

9. Cicek E, Aydin G, Akdogan M, et al. Effects of chronic ingestion of sodium fluoride on myocardium in a second generation of rats. Hum Exp Toxicol. 2005; 24(2): 79-87, doi: 10.1191/0960327105ht505oa, indexed in Pubmed: 15850282 .

10. Delker SL, Xue F, Li H, et al. Role of zinc in isoform-selective inhibitor binding to neuronal nitric oxide synthase . Biochemistry. 2010; 49(51): 10803-10810, doi: 10.1021/ bi1013479, indexed in Pubmed: 21138269.

11. Erdal S, Buchanan SN. A quantitative look at fluorosis, fluoride exposure, and intake in children using a health risk assessment approach. Environ Health Perspect. 2005; 113(1): 111-117, doi: 10.1289/ehp.7077, indexed in Pubmed: 15626657.

12. Fabiyi-Edebor TD. Vitamin C ameliorated cardiac autonomic neuropathy in type 2 diabetic rats. World J Diabetes. 2020; 11(3): 52-65, doi: 10.4239/wjd.v11.i3.52, indexed in Pubmed: 32180894.

13. Fuse $Y$, Kobayashi M. Conservation of the Keap1-Nrf2 System: An Evolutionary Journey through Stressful Space and Time. Molecules. 2017; 22(3), doi: 10.3390/molecules22030436, indexed in Pubmed: 28282941.

14. Ghosh J, Das J, Manna P, et al. Cytoprotective effect of arjunolic acid in response to sodium fluoride mediated oxidative stress and cell death via necrotic pathway. Toxicol In Vitro. 2008; 22(8): 1918-1926, doi: 10.1016/j. tiv.2008.09.010, indexed in Pubmed: 18845235.

15. Gold R, Kappos L, Arnold DL, et al. Placebo-controlled phase 3 study of oral BG-12 for relapsing multiple sclerosis. N Engl J Med. 2012; 367(12): 1098-1107, doi: 10.1056/ NEJMoa1114287, indexed in Pubmed: 22992073.

16. Goshman LM. Clinical toxicology of commercial products, By RE Gosselin, RP Smith, and HC Hodge. Williams and Wilkins, Baltimore 1984.

17. Gupta AR, Dey S, Saini M, et al. Protective effect ofTamarindus indicafruit pulp extract on collagen content and oxidative stress induced by sodium fluoride in the liver and kidney of rats. Toxicological \& Environmental Chemistry. 2014; 95(9): 1611-1623, doi: 10.1080/02772248.2014.890724.

18. Gupta AR, Dey S, Swarup D, et al. Effects of excessive fluoride ingestion on collagen protein and expression of type I collagen gene in skeletal muscles of rats. Fluoride. 2013; 46(3): 149-55. 
19. Hargrave BY. Autologous platelet rich plasma (platelet gel): an appropriate intervention for salvaging cardiac myocytes under oxidative stress after myocardial infarction. Anatomy \& Physiology. 2013; 04(01), doi: 10.4172/2161-0940.1000134.

20. He WW, Wang WY, Deng J, et al. L-NMMA and1400W, inhibitor of iNOS, attenuate the induction of iNOS and NO in primary rabbit costal chondrocytes by fluoride. Fluoride. 2020; 53(2): 220-238.

21. Itoh K, Ishii T, Wakabayashi N, et al. Regulatory mechanisms of cellular response to oxidative stress. Free Radic Res. 1999; 31(4): 319-324, doi: 10.1080/10715769900300881, indexed in Pubmed: 10517536.

22. Jakobs $P$, Serbulea $V$, Leitinger $N$, et al. Nuclear factor (erythroid-derived 2)-like 2 and thioredoxin-1 in atherosclerosis and ischemia/reperfusion injury in the heart. Antioxid Redox Signal. 2017; 26(12): 630-644, doi: 10.1089/ ars.2016.6795, indexed in Pubmed: 27923281.

23. Kojo S. Vitamin C: basic metabolism and its function as an index of oxidative stress. Curr Med Chem. 2004; 11(8): 1041-1064, doi: 10.2174/0929867043455567, indexed in Pubmed: 15078165.

24. Lawal AO, Lawal AF, Ologundudu A, et al. Antioxidant effects of heated garlic juice on cadmium-induced liver damage in rats as compared to ascorbic acid. J Toxicol Sci. 2011; 36(5): 549-557, doi: 10.2131/jts.36.549, indexed in Pubmed: 22008531.

25. Liu AJ, Li B, Yang M, et al. Sirtuin 1 mediates hydrogen sulfide-induced cytoprotection effects in neonatal mouse cardiomyocytes. Chinese Med J. 2017; 130(19): 2346, doi: $10.4103 \% 2 F 0366-6999.215328$.

26. Luo Q, Guo H, Kuang $P$, et al. Sodium Fluoride Arrests Renal G2/M Phase Cell-Cycle Progression by Activating ATM-Chk2-P53/Cdc25C Signaling Pathway in Mice. Cell Physiol Biochem. 2018; 51(5): 2421-2433, doi: 10.1159/000495899, indexed in Pubmed: 30537743.

27. Lusigi EM. Quality Assessment of Rain and Storm Water Runoff for Nairobi City Industrial and Sub-Urban Areas (Doctoral dissertation), University of Nairobi, 2017.

28. Martins RP, Hartmann DD, de Moraes JP, et al. Platelet-rich plasma reduces the oxidative damage determined by a skeletal muscle contusion in rats. Platelets. 2016; 27(8): 784-790, doi: 10.1080/09537104.2016.1184752, indexed in Pubmed: 27255146.

29. McDonagh MS, Whiting PF, Wilson PM, et al. Systematic review of water fluoridation. BMJ. 2000; 321(7265): 855-859, doi: $10.1136 / \mathrm{bmj} .321 .7265 .855$, indexed in Pubmed: 11021861.

30. Moi P, Chan K, Asunis I, et al. Isolation of NF-E2-related factor 2 (Nrf2), a NF-E2-like basic leucine zipper transcriptional activator that binds to the tandem NF-E2/AP1 repeat of the beta-globin locus control region. Proc Natl Acad Sci U S A. 1994; 91(21): 9926-9930, doi: 10.1073/ pnas.91.21.9926, indexed in Pubmed: 7937919.

31. Moraes VY, Lenza M, Tamaoki MJ, et al. Platelet-rich therapies for musculoskeletal soft tissue injuries. Cochrane Database Syst Rev. 2014(4): CD010071, doi: 10.1002/14651858. CD010071.pub3, indexed in Pubmed: 24782334.

32. Mostafavi-Pour Z, Ramezani F, Keshavarzi F, et al. The role of quercetin and vitamin C in Nrf2-dependent oxidative stress production in breast cancer cells. Oncol Lett. 2017;
13(3): 1965-1973, doi: 10.3892/ol.2017.5619, indexed in Pubmed: 28454351.

33. Nair V, O'Neil C, Wang P. Malondialdehyde. Encyclopedia of Reagents for Organic Synthesis. 2008, doi: 10.1002/047084289x.rm013.pub2.

34. Ngoc TD, Son YO, Lim SS, et al. Sodium fluoride induces apoptosis in mouse embryonic stem cells through ROS-dependent and caspase- and JNK-mediated pathways. Toxicol Appl Pharmacol. 2012; 259(3): 329-337, doi: 10.1016/j. taap.2012.01.010, indexed in Pubmed: 22285274.

35. Oyagbemi AA, Omobowale TO, Asenuga ER, et al. Sodium fluoride induces hypertension and cardiac complications through generation of reactive oxygen species and activation of nuclear factor kappa beta. Environ Toxicol. 2017; 32(4): 1089-1101, doi: 10.1002/tox.22306, indexed in Pubmed: 27378751.

36. Padayatty SJ, Katz A, Wang Y, et al. Vitamin C as an antioxidant: evaluation of its role in disease prevention. J Am Coll Nutr. 2003; 22(1): 18-35, doi: 10.1080/07315724.2003.10719272, indexed in Pubmed: 12569111.

37. Peng W, Xu S, Zhang J, et al. Vitamin c attenuates sodium fluoride-induced mitochondrial oxidative stress and apoptosis via Sirt1-SOD2 pathway in F9 cells. Biol Trace Elem Res. 2019; 191(1): 189-198, doi: 10.1007/s12011018-1599-0, indexed in Pubmed: 30565018.

38. Pi H, Xu S, Reiter RJ, et al. SIRT3-SOD2-mROS-dependent autophagy in cadmium-induced hepatotoxicity and salvage by melatonin. Autophagy. 2015; 11(7): 1037-1051, doi: 10.1080/15548627.2015.1052208, indexed in Pubmed: 26120888.

39. Piantadosi CA, Carraway MS, Babiker A, et al. Heme oxygenase-1 regulates cardiac mitochondrial biogenesis via Nrf2-mediated transcriptional control of nuclear respiratory factor-1. Circ Res. 2008; 103(11): 1232-1240, doi: 10.1161/01.RES.0000338597.71702.ad, indexed in Pubmed: 18845810.

40. Popovic LM, Mitic NR, Miric D, et al. Influence of vitamin $C$ supplementation on oxidative stress and neutrophil inflammatory response in acute and regular exercise. Oxid Med Cell Longev. 2015; 2015: 295497, doi: 10.1155/2015/295497, indexed in Pubmed: 25802681.

41. Saif-Elnasr M, Abdel Fattah SM, Swailam HM. Treatment of hepatotoxicity induced by $\gamma$-radiation using platelet-rich plasma and/or low molecular weight chitosan in experimental rats. Int J Radiat Biol. 2019; 95(11): 1517-1528, doi: 10.1080/09553002.2019.1642538, indexed in Pubmed: 31290709.

42. Shenoy PS, Sen U, Kapoor S, et al. Sodium fluoride induced skeletal muscle changes: Degradation of proteins and signaling mechanism. Environ Pollut. 2019; 244: 534-548, doi: 10.1016/j.envpol.2018.10.034, indexed in Pubmed: 30384060.

43. Smith RE, Tran K, Smith CC, et al. The Role of the Nrf2/ARE antioxidant system in preventing cardiovascular diseases. Diseases. 2016; 4(4), doi: 10.3390/diseases4040034, indexed in Pubmed: 28933413.

44. Spartalis E, Tomos P, Moris D, et al. Role of platelet-rich plasma in ischemic heart disease: An update on the latest evidence. World J Cardiol. 2015; 7(10): 665-670, doi: 10.4330/wjc.v7.i10.665, indexed in Pubmed: 26516421. 
45. Viswanathan G, Gopalakrishnan S, Siva llango S. Assessment of water contribution on total fluoride intake of various age groups of people in fluoride endemic and non-endemic areas of Dindigul District, Tamil Nadu, South India. Water Res. 2010; 44(20): 6186-6200, doi: 10.1016/j.watres.2010.07.041, indexed in Pubmed: 20728198.

46. Wang D, Shi JQ, Liu FX. Immunohistochemical detection of proliferating cell nuclear antigen in hepatocellular carcinoma. World J Gastroenterol. 1997; 3(2): 101-103, doi: 10.3748/wjg.v3.i2.101, indexed in Pubmed: 27041957.

47. Wakabayashi N, Itoh K, Wakabayashi J, et al. Keap1-null mutation leads to postnatal lethality due to constitutive Nrf2 activation. Nat Genet. 2003; 35(3): 238-245, doi: 10.1038/ng1248, indexed in Pubmed: 14517554.

48. Xu S, Gao Y, Zhang Q, et al. SIRT1/3 activation by resveratrol attenuates acute kidney injury in a septic rat model. Oxid Med Cell Longev. 2016; 2016: 7296092, doi: 10.1155/2016/7296092, indexed in Pubmed: 28003866.
49. Yildirim S, Ekin S, Huyut Z, et al. Effect of chronic exposure to sodium fluoride and 7, 12-dimethylbenz [a] anthracene on some blood parameters and hepatic, renal, and cardiac histopathology in rats. Fluoride. 2018; 51(3): 278-290.

50. Yin B, Di L, Tang S, et al. Vitamin CNa enhances the antioxidant ability of chicken myocardium cells and induces heat shock proteins to relieve heat stress injury. Res Vet Sci. 2020; 133: 124-130, doi: 10.1016/j.rvsc.2020.09.008, indexed in Pubmed: 32977120.

51. Zaki SM, Algaleel WaA, Imam RA, et al. Mesenchymal stem cells pretreated with platelet-rich plasma modulate doxorubicin-induced cardiotoxicity. Hum Exp Toxicol. 2019; 38(7): 857-874, doi: 10.1177/0960327119842613, indexed in Pubmed: 30991846.

52. Zhao WP, Wang HW, Liu J, et al. Positive PCNA and Ki-67 expression in the testis correlates with spermatogenesis dysfunction in fluoride-treated rats. Biol Trace Elem Res. 2018; 186(2): 489-497, doi: 10.1007/s12011-018-1338-6, indexed in Pubmed: 29748930. 